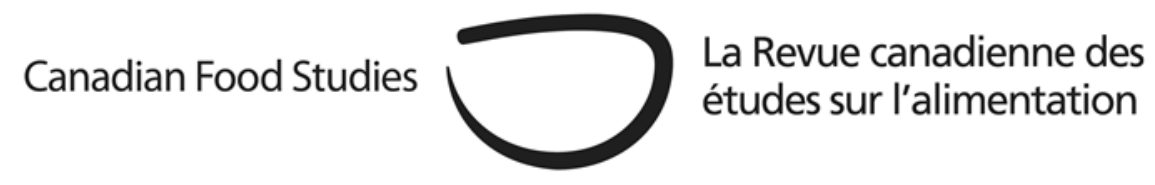

Field Report

\title{
Etuaptmumk-two eyed seeing: Bringing together land-based learning and online technology to teach Indigenous youth about food
}

\author{
Renee Bujold ${ }^{a *}$ and Ann Fox ${ }^{b}$, Kerry Prosper ${ }^{b}$, Kara Pictou ${ }^{c}$, Debbie Martin ${ }^{a}$ \\ ${ }^{a}$ Dalhousie University \\ bSt. Francis Xavier University \\ 'The Confederacy of Mainland Mi'kmaq
}

\begin{abstract}
In 2019 we began an intergenerational land-based learning program with the goal of engaging a group of Mi'kmaw youth from a rural community in Nova Scotia with their traditional foodways. When COVID-19 and the physical distancing restrictions hit Nova Scotia, however, this changed how we implemented the project. During the early phases of strict isolation, we turned to technology to connect us with youth. As public health protocols changed over a tenmonth period, we drew on a combination of learning approaches to share Mi'kmaw traditional knowledge. This paper describes the dilemmas we faced as we considered what initially seemed like a paradoxical relationship of using online technology to promote land-based learning. Our aim is to not only draw attention to what we believe to be the centrality of the land in understanding Indigenous foodways, but also the potential for online technology to enhance youth engagement on and with the land. Our experience suggests that communication technology can support land-based learning about traditional foodways and culture, but that there are challenges such as access to and expertise in using it related to implementing land-based pedagogy in virtual environments. A major insight was that an Etuaptmumk-Two-Eyed Seeing lens allowed us to include both Western and Indigenous knowledges in the program and helped us adapt to the unanticipated logistical challenges we faced. We came to see that online
\end{abstract}

*Corresponding author: rn644459@dal.ca

DOI: $10.15353 /$ cfs-rcea.v8i4.466

ISSN: 2292-3071

CC BY-SA 
technology is not only a product of 'Western' knowledge, but also a powerful resource through which Indigenous peoples can own, celebrate, and share their culture.

Keywords: Land-based learning; two-eyed seeing; technology; Indigenous health; youth; Indigenous foodways

Etuaptmumk-two-eyed seeing: Bringing together land-based learning and online technology to teach Indigenous youth about food

We begin by acknowledging that we reside in Mi'kma'ki, the ancestral and unceded territory of the Mi'kmaq people. It is essential to understand the history that has brought us to reside on the land, and to seek to understand our place within our shared history as treaty people. We, a team composed of health researchers, Indigenous Knowledge Keepers, and dietitians, see the centrality of the land and its foods as sources of health and resilience. Despite the past and present forces of colonization within Mi'kma'ki that have attempted to silence their traditional knowledges, Mi'kmaq peoples continue to harvest foods in accordance with their long held spiritual understanding of the relationships between all living things, referred to as "Netukulimk" (Prosper et al., 2011). This complex knowledge system continues to be formed, and communities recognize the importance of passing this knowledge on to the next generation in increasingly different ways within our modern world.

Through this field report we aim to share our experiences of implementing the Land2Lab pilot project, a community-based intergenerational traditional foods program that was originally designed to engage youth in land-based learning but was later modified to include online components. We explain the concept of Etuaptmumk-Two-Eyed Seeing (E-TES) and how this ontological lens has impacted the project's direction since the occurrence of COVID-19. We draw upon E-TES to explore and reflect on the relationship between land-based and online technologies during the COVID-19 pandemic while trying to implement the program in the Paqtnkek Mi'kmaw Nation.

The Land2Lab Project

The Land2Lab project was built upon a community action approach that positions community members as equal members of the research team, the voices of community needs, and the experts in determining how to meet those needs (Baum et al., 2006). Kara, a member of the Paqtnkek Mi'kmaw Nation and now an employee with The Confederacy of Mainland Mi'kmaq (CMM), was an undergraduate student at St. Francis Xavier University (StFX) in the Human Nutrition program. During that time, she pursued a directed study titled Reclaiming Traditional Foods in $M i$ 'kma'ki when she became aware of interest among youth in learning more about traditional 
foodways. Kara, along with Kerry, an Elder from Paqtnkek, researcher, and Inaugural Knowledge Keeper at StFX recognized the importance of sharing community-held knowledges on the land with youth and Elders. In 2019, in partnership with CMM and StFX, the Land2Lab project was created to bring youth and Elders together on the land to teach and share traditional knowledges.

The Land2Lab project was developed with the goal of engaging youth from Paqtnkek Mi'kmaw Nation in their traditional foodways, which are the foods, knowledges, and practices handed down for generations that help connect us to culture (Rearick, 2009). The intended program featured Elders sharing stories, food gathering techniques and preparation methods, and food with youth through activities focused on each of the four seasons. The overarching goal of this project was to contribute to cultural, environmental, and community well-being by promoting traditional knowledges about Mi'kmaw foodways and the interconnectedness of climate, food, and health. The specific research and program objectives were to:

1) Provide a vehicle for intergenerational knowledge sharing of traditional foodway practices.

2) Provide youth with employable food skills.

3) Explore the potential for Etuaptmumk-Two-Eyed Seeing (E-TES) as an ontological lens for sharing both Indigenous and Western food knowledge.

4) Inspire youth to see themselves pursuing careers related to food, science, and environment.

5) Understand how land-based learning contributes to these goals.

The planned program consisted of four half-day workshops, one for each season, and would take place over the course of one year. During these workshops, youth were to meet with Elders on the land to share stories and learn about traditional food gathering and harvesting practices, then return together to the community kitchen or StFX food lab to learn about food science and food safety, prepare food according to traditional methods, and enjoy eating it together. On February 16, 2020, we had completed our winter eel fishing day, the first of four workshops, where Kerry taught ten youth how to shape their own fishing spears on a carving bench, trek safely across the frozen harbour to saw holes in the ice, provide a tobacco offering of thanks to Creator, and catch eels with their spears under the ice.

During this workshop, we noticed two phenomenon that have inspired this field report: even while on the land and ice, youth were using their phones but were still extremely present and engaged in the eel fishing activities. There was a special moment during the workshop when this became evident to us. We had been on the ice for about two hours when we caught the first eel. This was an exciting moment for everyone, especially when we noticed many bald eagles flying over our heads at the exact moment the first eel was caught. The youth acknowledged this message from Creator and gifted the first eels to the eagles. They then enjoyed taking pictures and videos of the eagles diving down from the sky, swiftly picking the eels up with their talons. Elders encouraged this and acknowledged the significance of this encounter. The Elders used it 
as a teaching opportunity to tell youth about the interconnectedness of nature and the food chain, as well as the youths' position within this system as human beings.

\section{Responding to COVID-19}

The youth were planning a community feast with the caught eels, a delicacy for the Elders, when COVID-19 hit Nova Scotia in early March and prevented this event from taking place. We initially considered canceling or postponing the project but subsequently decided to adapt our approaches to the circumstances. Over the following ten months, we were able to draw upon a combination of learning and engagement approaches to share traditional knowledges with youth. At the height of COVID-19 isolation protocols, we turned to technology to connect us with youth where we implemented virtual activities rather than bringing groups of youth and Elders together physically on the land. As public health protocols changed over time, however, we were able to blend our approaches to include both online and in-person components.

Initially we were face to face on the land, ice fishing for eels, with other land-based activities planned for the following seasons. When restrictions hit, however, we got word about the iNaturalist app, along with other technology-based initiatives, from the CMM Climate Monitoring Program who were encouraging youth to get out on the land with the app. The iNaturalist app is a citizen science project and online social network that aims to map and share observations of biodiversity across the globe (iNaturalist Network, 2020). CMM was using this app to gather biodiversity and bio-indicator data within Mi'kmaq communities across the mainland. While we were unable to meet in-person, we moved our efforts towards supporting this initiative of getting youth on the land to collect data within their communities.

In the early fall we were able to gather as a small group again, but not yet with Elders. During this time were able to complete two successful kitchen workshops with a group of ten youth at their local community centre where we made wild blueberry jam and a three sisters' soup (squash, beans, and corn). Kara used Facebook to share information and posters about these workshops with members of her community. We also relied on Kara as our Knowledge Keeper to lead these workshops, and we highlighted the importance of food safety and food skills throughout these sessions. In the early winter we were finally able to bring youth together with an Elder to make luskinikn (bannock), which we then topped with the wild blueberry jam that we prepared in an earlier workshop. Following this, restrictions tightened again, and as the pilot wound down, we moved back to distanced-online approaches to evaluate and gather youth's perspectives of the Land2Lab project.

As we reflected about the workshop that was able to happen prior to COVID-19, we realized that alongside the re-emergence of land-based opportunities for Indigenous youth, we cannot ignore the fundamental role that online technologies have in shaping their everyday life experiences. With the rise of online gaming, social media, texting, online learning, etc., we recognize that technology and the Internet are inescapable elements that characterize the 
experience of being a young person today (Radoll, 2014), and that Indigenous organizations are already using technology to support their communities. Yet, with COVID-19 and having to restructure our program delivery to a blended approach, we soon noticed both the advantages and challenges of using online technology to promote land-based learning, and realized we know little about whether or how technology and the use of the Internet might interact with Indigenous knowledge systems and land-based learning.

\section{Etuaptmumk-two-eyed seeing}

While we planned to draw upon the concept of E-TES from the early stages of planning the project, the changes imposed by the pandemic led us to think about it in ways we had not anticipated. Etuaptmumk is a Mi'kmaq word that represents the gifts of having multiple perspectives. Elders Albert and the late Murdena Marshall, along with Dr. Cheryl Bartlett from Cape Breton University, further coined the term Two-Eyed Seeing to describe the metaphorical use of one eye to see Indigenous ways of knowing and the other eye to see Western ways, in order to respect and utilize the best of both perspectives (Bartlett et al., 2012; Bartlett et al., 2015). This has been particularly useful when considering how we interact with both our natural and technological environments. Two-Eyed Seeing allows us to acknowledge the entirety of Indigenous knowledge systems alongside Western knowledges and worldviews, so that we can continuously 'weave back and forth' between knowledges to create meaningful and respectful research and community-based programs that recognize the complexity of being a young person today (Bartlett et al., 2012; Institute for Integrative Science \& Health, nd). We had intended to marry traditional knowledge about food growing, gathering, procuring, storing, preparing, and sharing with Western science on the nutritional content of traditional foods, microbiology insights on food preservation, and climate science information to reinforce the health and sustainability benefits of traditional methods. Using technology to tell stories and/or encourage land-based experiences had not crossed our minds. We therefore wondered how online technologies and land-based learning might intersect. We believe that there are some experiences and learnings that need to take place on the land but struggled with how to reach youth and get them on the land without physically gathering there together.

\section{Land-Based Education}

Land-based learning typically uses an Indigenized and environmentally focused approach to education by first recognizing the deep physical, mental, and spiritual connection to the land that is part of Indigenous cultures (Styres \& Zinga, 2011). It offers experiential education on the land that is grounded within Indigenous knowledges and pedagogy, where learning occurs on the land and from the land. Research increasingly shows that learning in an outdoor environment has 
mental health benefits, improves understanding for active learners, and can help students develop environmental awareness and a connection to the land (Cherpako, 2019). Within Indigenous pedagogy, learning has been conceptualized as a personal and complex journey that requires internal reflection and integration of one's learnings over time (Battiste \& Henderson, 2009), and the cultivation and reflection of the relationship between people and the land is believed to be what allows for knowing and learning to occur (Battiste, 2013). Indigenous knowledge systems, however, have been historically ignored, neglected, or rejected by European and Western cultures, who instead have privileged their own perspectives and knowledge systems above the rest. This prioritization and neglect towards the complex relationship that we, as human beings, have to our natural environment is ultimately what has resulted in the climate crisis (Brugnach et al., 2017). In Western society, we have privileged the ego above our ecological environment (Scharmer \& Kaufer, 2013), and now as a scientific community we are increasingly turning towards Indigenous peoples and Knowledge Keepers to lead the way and help us re-frame our relationship with the land and its foods.

Our food inextricably connects us to the land, and land-based education is particularly well-suited for teaching Indigenous youth about their traditional foodways (Big-Canoe \& Richmond, 2014; Cidro et al., 2015). This became evident to us during the Elder-led eel fishing workshop. When we got on the ice, we soon noticed that there were square holes that previous eel fishers had made with power saws. Kerry, however, taught us that this was not the most effective way to fish for eel. He went on to demonstrate that making a circular hole with a hand saw allows for your spear to move much more steadily along the perimeter of the hole, giving you more area to fish for eel under the ice, meaning a better chance of catching eels. The youth were watching his every move and the older youth made their own holes with his guidance. Despite the cold, youth patiently fished for hours, determined to catch eels with the spears they had made. From this we learned that without the presence of intergenerational land-based learning, the skills needed to learn how to ice fish could not be passed on.

While it is recognized that land-based education is a necessary and effective way to teach Indigenous youth about their culture and traditional foodways (Big-Canoe \& Richmond, 2014; Cidro et al., 2015; Battiste, 2013; Cherpako, 2019), it does come with its own challenges. For learning to occur, for instance, youth and their communities need to be able to access the land and its foods. This is becoming increasingly difficult due to the alarming effects of climate change and the fear that Elders' knowledges will not be sufficiently passed on to today's youth (Ross, 2016). Teaching youth about traditional foodways without access to safe clean water, land, ice, or air is the reality for many (Richards et al., 2019). Climate change and issues surrounding the land and health cannot be ignored when teaching about traditional foodways. In fact, our own plans to engage youth in eel fishing with Elders was delayed several weeks by new weather patterns wherein the harbour did not freeze, which is increasingly the norm.

Land-based education encourages the celebration of Indigenous culture and knowledges, while also demonstrating to youth the need to combat and protect against the effects of climate change and colonization. Yet, we have learned that these programs are resource-heavy and 
require a lot of community involvement and leadership. There can be barriers to implementing successful land-based intergenerational programs, such as cost and transportation, along with liabilities associated with being on the land, the availability of Elders and Knowledge Keepers, and the presence of community supports. Additionally, like any other youth-based program, it may be difficult to get youth on the land in the first place, and we wonder if our experience of integrating online technologies might present a way of mitigating some of these barriers. Arguably, most people would agree that connection to the land, sea, air, water, ice, and its foods cannot truly be replicated using technology or within a classroom setting. At the same time, the photos of the eagles and subsequent Tweets seemed to reinforce the pride the youth felt for having successfully fished in traditional ways, while engaging their online friends in the process.

\section{Online Technology}

Although we acknowledge that there are exceptions related to equitable access, we can generally say that youth, both Indigenous and non-Indigenous, represent the first generation to grow up with online technologies at their fingertips (Radoll, 2014). It is the first generation to have spent their entire lives surrounded by computers, cell phones, and all the other technology that we use today. For this field report, online technologies will be broadly defined as any technological platform or device that youth utilize to share, engage with, and gather information that is connected to the Internet. We have kept this definition broad, as the Land2Lab project activities are continuously changing based on the needs of community members.

Despite challenges of access and adoption of digital connectivity, the use of the Internet and social media has spread within Indigenous communities (Castleton, 2018). In the past 20 years, the Internet and its use has grown into the largest, most accessible database of information ever created (Castleton, 2018). It has changed the way people communicate and connect, do business, and think about knowledge and learning (Prensky, 2001). The Internet has become more than just a medium to access information; it increasingly connects communities and provides access to important services (Campbell, 2018). While there have been differing views regarding the acceptance and use of the Internet within Indigenous communities, its access is fundamental for the development of basic rights such as social security, cultural expression, and conservation (Castleton, 2018).

Online technologies are making education more accessible than ever before, especially now in the midst of a global pandemic. Online education relies on the Internet for sharing and teaching information, and with this simple definition comes many ways in which youth can engage with their learning though online technology. Through online education, students can access information in many forms including audio, video, text, graphics, virtual and interactive programs, and even live chats (Anderson, 2008). Many young learners today, because of their 
experiences with and proficiency in online technologies, are able to obtain information quickly and can access perspectives that may not be shared with them in a classroom setting (Prensky, 2001). This may be different from previous generations who relied on learning through oral and written teachings, which may not be the preferred method among young learners today.

Online technologies provide Indigenous youth with a way to explore and express their identities in ways that may not be possible elsewhere (Edmonds et al., 2012; Lumby, 2010). Having this space for exploration is important for Indigenous youth in Canada, as Western knowledges and worldviews have been prioritized in learning environments, which has limited Indigenous students' ability to understand, protect, and utilize their Indigenous knowledge systems (Battiste, 2013). This favouring of Western knowledges may create a learning environment for Indigenous students where they feel that they do not belong and where their cultural knowledges, traditions and values are not recognized or celebrated in parallel (Kirkness $\&$ Barnhart, 2001). If a young person's culture and cultural knowledges are not shared within their learning space, this could lead to identity struggles, as one's culture provides a measure of sameness and support while entering young adulthood (Chandler \& Lalonde, 2008). The Internet, however, allows for the existence of multiple perspectives and worldviews which may uniquely support Indigenous youth in forming a learning space and online community that encourages their Indigenous identities. This sense of community is significant for Indigenous youth, as the Indigenous population in Canada is on average younger than the general Canadian population and Indigenous peoples in Canada, while moving towards urban centers, are more likely than other Canadians to live in small, remote communities (Statistics Canada, 2016). Social media allows youth to connect with relations who may not be close by and with people outside of their communities to further broaden their understanding of their culture and the surrounding world.

Due to technological advancements, today's youth are living and learning differently than previous generations which complicates how Indigenous knowledges have traditionally been passed on. Now, youth can access information about Indigenous culture online, and within Mi'kma'ki, there is a growing online presence of Mi'kmaw Knowledge Keepers and organizations dedicated to highlighting and sharing their culture. For example, on Instagram and Facebook there are several accounts that showcase land-based activities and intergenerational knowledge sharing surrounding Netukulimk. Sharing images and the experiences of Indigenous youth while on the land on social media can be a contemporary and complimentary way to store, protect, and celebrate Indigenous knowledges and culture.

Through exploring online technology, we have become more aware of its role within Indigenous youth's lives, how it can potentially help preserve and celebrate Indigenous knowledge systems, and how Indigenous communities are already actively utilizing online technologies in ways that support their culture. Through this, we see online technologies as a way to support Indigenous knowledges. Yet, we still question how land-based learning and online technologies may come together when considering E-TES. 


\section{Bringing Together Online Technology and Land-based Learning}

There is a lack of empirical research on how to facilitate land-based learning (Bartmes \& Shukla, 2020), and on integrating online technologies into land-based programs as a way to teach youth about food. Etuaptmumk-Two-Eyed Seeing (E-TES) was initially meant to be a way for us to value and support youth in learning about both Indigenous and Western perspectives surrounding food (learning about traditional foodways, while also learning about food safety, for example). While there is also a lack of empirical data on how to apply E-TES, we believe that it is what allowed us to navigate our program delivery throughout COVID-19 and to challenge our own perspectives surrounding technology use. Little did we know how helpful E-TES would be in allowing us to 'weave' between two perspectives when we needed to: the Indigenous eye which values land-based learning, and the Western eye which values technology. It was a fruitful way for seeing and responding to things in ways we had not anticipated. For instance, instead of cancelling the program we were able to modify and move it online according to community needs.

Through E-TES, we can begin to see the potential relationship between land-based and online learning and how these two approaches can reinforce and support each other in teaching youth about their traditional foodways. We realize, however, that there may be tensions surrounding this idea. Understanding the historical mistreatment of Indigenous peoples by Canadian government and society, we are aware that there may be apprehension concerning the integration of online technologies into land-based pedagogies, as the use of Western technologies and pedagogies could be seen as further perpetuating issues of colonization. Russell Means, in his powerful speech in 1980, warns against adopting aspects of Western culture because it could be detrimental to the Indigenous way of life. Using online technologies could be seen as leaving behind Indigenous knowledges, traditions, and ways of relating to the world. Means' (1980) argument is valid in the sense that there are differences between the Indigenous and Western knowledge systems, and that Western society continues to mistreat Indigenous peoples, even on the Internet. There are concerns surrounding the protection of Indigenous knowledge when it is shared online. For instance, there might be occurrences where websites try to benefit from or claim Indigenous Knowledges as their own, when in reality the hosts of these sites may have no knowledge of Indigenous Knowledge systems or history, further perpetuating issues of colonization. Teaching youth how and where to safely gather and share their knowledges online should be prioritized. The iNaturalist app, for example, has an 'obscured' option when posting observations of culturally significant species to help ensure that the data, and location of the species remains protected (iNaturalist Network, 2020). 
Now, however, E-TES gives us the ability to open our minds to the possibilities of multiple worldviews and encourages us to see value in both perspectives. In the past, we can see that the Western eye has been prioritized within Canadian society, so much so that the Indigenous eye has been closed shut. Now, we believe Indigenous knowledges are fundamental in ensuring the sustained health of Indigenous peoples and the planet. Western pedagogies have been notoriously prioritized within Canada's educational system. This hierarchy has influenced how we teach today's youth and what information we have taught them to be valid or true. For instance, Cajete (1999) states that Western pedagogy is privileged in science, and this leads students to perceiving themselves as separate and apart from the world that they are studying. This approach to science is fundamentally different from Indigenous sciences, where Indigenous peoples view themselves in relation to the natural world, not apart from it.

This is where we asked the question: Does technology remove us from our natural world, or can it bring us closer? E-TES supports the consideration of multiple worldviews and perspectives and encourages collaboration in determining how different worldviews can come together to solve social issues, such as the over-prioritization of Western knowledges in education. To support future opportunities for Indigenous youth, Borden and Wiseman (2016) discuss the importance of the integration of Indigenous perspectives into Western pedagogies, and state that this process should not be about specific content and control, but rather about pedagogy and how engagement in teaching and learning allows for growth in mind, body, spirit, and heart. They also quote Mohawk scholar Doolittle (2006), who challenges us to consider how we might bring scientific knowledges into Indigenous culture, rather than how science might be pushed onto Indigenous culture. While this perspective values both Western and Indigenous knowledges as being critical for youth's education, it places greater emphasis on how these knowledges are taught and framed as being influential to how youth perceive themselves and the world around them.

Through this perspective, we can see technology as a tool, and how this tool is used will determine how beneficial it will be in supporting land-based learning. Using technology with a Western worldview that does not inherently value the natural world could further remove us from it, whereas using technology with an Indigenous perspective that encourages us to seek out information relating to the land and our relationship to it could allow us to use technology in a way that supports our connection to nature and encourages us to get outside. Through an E-TES lens, we can see technology as not being inherently Western, but as new way to communicate that any community, culture, or society can benefit from if they are able to harness its power. While online technologies were created out of Western society, Indigenous artists, journalists, activists, and storytellers are using technology in innovative ways to take charge of their culture and express their voices despite colonial influences on the Internet (Carlson \& Dreher, 2018). We believe it is possible that online technologies could be (and are already) apart of Indigenous culture and pedagogy in ways that support and uphold Indigenous knowledges and values.

We saw this during our eel fishing expedition where traditional practices were able to coexist with technology. In fact, the Internet and social media have become crucial elements in 
maintaining Indigenous identity through sharing of information (Hicks \& White, 2000). In Canada's North, for example, culture and technology could be said to mutually adapt and fortify each other in the shifting circumstances of the Arctic (Hicks \& White, 2000). In Castleton's (2018) study, he found that Inuit students illustrated the importance of Facebook groups in their daily lives, as one of them said, "[through Facebook] I learn more about old ways and how things were done before." The young participants of this study referred to a Facebook group called "Inuit Hunting Stories of the Day." This type of group, which shares stories about hunting and traditional foodways, was acknowledged by the participants as a good way to present Inuit culture, to know their own identity, and to learn traditional techniques and knowledge for hunting and survival (Castleton, 2018). We have learned that Indigenous youth are avidly utilizing online technologies in ways that suit their identity, culture, and interactions with the wider world.

E-TES allows us to consider the best of two seemingly divergent worldviews. It allows us to see that Indigenous knowledge systems have different strengths than Western knowledge systems, and we need to prioritize these teachings and perspectives when supporting the health of Indigenous communities in engaging in their traditional foodways. Through this field report we have discussed both the benefits of land-based learning and online technologies, and we value both. Through E-TES we have come to believe that being on the land, and the feeling of being in nature, cannot be formed online. Yet, online technologies can support youth in getting outside in the first place so that they can learn about their food and culture. Better yet, youth can engage with online communities that support their identities and allow them to share their knowledge and experiences with others. Online technologies, in many ways, have become a tool of youth activism and resistance towards colonization, where youth are reclaiming their knowledge systems, both online and on the land. Today's Indigenous youth are simultaneously technology users and the Knowledge Keepers of tomorrow. Utilizing technology may help to ensure that they are able to preserve the traditional knowledges that Elders pass on to them, as well as providing the means to share and pass on their culture with future generations. Indigenous peoples have long been innovators and developers of technologies that have enabled their survival on the land. Similarly, in our changing world, Indigenous peoples have the right to determine how online technology will be used to support their communities and govern their lands in the future.

\section{Conclusion}

Seeing the way that Mi'kmaw youth were able to interact with both the land and online technologies during our project workshops and through discovering the presence of other online 
land-based initiatives within Mi'kma'ki, we have been able to consider the role of technology in youth's lives and the potential relationship between land-based programming and technology. The unique circumstances of COVID-19 have allowed us to begin a conversation surrounding how land-based and online learning can come together to teach youth about their traditional foodways. Through E-TES we can see the strengths in considering multiple worldviews, while acknowledging the harm that has been caused by privileging and holding one perspective above the rest. Online technologies create opportunities for youth to engage in their culture, to further support the sharing and learning of Indigenous traditional knowledges such as Netukulimk, and the sharing and promotion of land-based activities. Through E-TES we have come to recognize the importance of generating a connection with the land. Online technologies can support this connection but cannot replicate it. Historically, we have tried through the Western eye to understand the natural world by removing ourselves from it. Now, we can learn to see and value the Indigenous eye and the spiritual lessons and practices it can instill within us. Getting on the land and learning these lessons and practices is imperative. Moving forward, we can begin to look at this relationship with the aim of getting youth on the land while sharing their experiences with their communities. Ultimately, we see online technologies as a bridge connecting youth to their natural environment, supporting them in preserving and revitalizing their traditional foodways and cultural knowledges.

Acknowledgements: We would like to acknowledge the Centre of Innovation and Employment at StFX for funding the pilot project, along with The Confederacy of Mainland Mi'kmaq Climate Monitoring Program. We thank the Paqtnkek Mikmaw First Nation and St Francis Xavier University Human Nutrition Department.

\section{References}

Anderson, T. (2008) The theory and practice of online learning. AU Press, Athabasca University.

Bartlett, C., Marshall, M. \& Marshall, A. (2012). Two-Eyed Seeing and other lessons learned within a co-learning journey of bringing together Indigenous and mainstream knowledges and ways of knowing. Journal of Environmental Studies Science, 2: 331-340 https://doi.org/10.1007/s13412-012-0086-8

Bartlett, C., Marshall, M., Marshall, A., \& Iwama, M. (2015). Integrative science and two-eyed seeing: Enriching the discussion framework for health communities. In Hallstrom, K., Guehlstorf, N., \& Parkes, M. (Eds.) Ecosystems, society and health: Pathways through diversity, convergence and Integration, 280- 326. McGill-Queens University Press.

Bartmes, N., \& Shukla, S. (2020). Re-envisioning land-based pedagogies as a transformative third space: perspectives from university academics, students, and Indigenous 
knowledge holders from Manitoba, Canada. Diaspora, Indigenous and Minority

Education, 14(3), 146-161. https://doi.org/10.1080/15595692.2020.1719062

Battiste, M. (2013). Decolonizing education: Nourishing the learning spirit. Purich Publishing Limited.

Battiste, M., \& Henderson, J. S. (2009). Naturalizing Indigenous Knowledge in Eurocentric education. Canadian Journal of Native Education, 32(1): 5-18. https://acurriculumjourney.files.wordpress.com/2014/04/battiste-henderson-2009naturalizing-indigenous-knowledge-in-eurocentric-education.pdf

Baum, F., MacDougall, C., \& Smith, D. (2006). Participatory action research. Journal of Epidemiology and Community Health, 60(10), 854-857. https://doi.org/10.1136/jech.2004.028662

Borden, L. \& Wiseman, D. (2016) Considerations from places where Indigenous and Western ways of knowing, being, and doing circulate together: STEM as artifact of teaching and learning, Canadian Journal of Science, Mathematics and Technology Education, 16(2), 140-152, https://doi.org/10.1080/14926156.2016.1166292

Big-Canoe, K., \& Richmond, C. A. M. (2014). Anishinabe youth perceptions about community health: Toward environmental repossession. Health \& Place, 26, 127-135. https://doi.org/10.1016/j.healthplace.2013.12.013

Brugnach, M., Craps, M., \& Dewulf, A. (2017). Including Indigenous peoples in climate change mitigation: Addressing issues of scale, knowledge and power. Climatic Change, 140(1), 19-32. https://link.springer.com/article/10.1007\%2Fs10584-014-1280-3

Campbell, J. (2018). Empowerment through connectivity: 2018 Indigenous connectivity summit community report. https://www.internetsociety.org/wpcontent/uploads/2019/01/2018-Indigenous-Connectivity-Summit-CommunityReport_EN.pdf

Castleton, A. (2018). Technology and Inuit identity: Facebook use by Inuit youth. AlterNative: An International Journal of Indigenous Peoples, 14(3), 228236. https://doi.org/10.1177/1177180118782993

Cajete, G. (1999). The Native American learner and bicultural science education. In K. Swisher \& J. Tippeconnic (Eds.). Next steps: Research and practice to advance Indian education. ERIC Clearinghouse on Rural Education and Small Schools.

Carlson, B., \& Dreher, T. (2018). Introduction: Indigenous innovation in social media. Media International Australia, 169(1), 16-20. https://doiorg.ezproxy.library.dal.ca/10.1177\%2F $1329878 X 18803798$

Cidro, J., Adekunle, B., Peters, E., \& Martens, T. (2015) Beyond food security: Understanding access to cultural food for urban Indigenous People in Winnipeg as Indigenous food sovereignty. Canadian Journal of Urban Research, 24(1), 24-43. Retrieved from https://searchproquestcom.ezproxy.library.dal.ca/docview/1769724360?accountid=10406

Cherpako, D. (2019). Making Indigenous-led education a public policy priority: The benefits of land-based education and programming. Samuel Centre for Social Connectedness. 
https://www.socialconnectedness.org/wp-content/uploads/2019/10/Land- BasedEducation-Pamphlet.pdf

Chandler, M. J. \& Lalonde, C. E. (2008). Cultural continuity as a protective factor against suicide in First Nations youth. Horizons: A special issue on Aboriginal youth, hope or heartbreak: Aboriginal youth and Canada's future, 10(1), 68-72. https://www.researchgate.net/publication/239921354_Cultural_Continuity_as_a Protecti ve Factor_Against_Suicide in_First_Nations_Youth

Doolittle, E. (2006) Mathematics as medicine. In Liljedahl P. (Ed ) Proceedings of the 2006 Annual Meeting of the Canadian Mathematics Education Study Group Conference pp 1725. C'MESG

Edmonds, F., Rachinger, C., Waycott, J., Morrissey, P., Kelada, O., \& Nordlinger, R. (2012). Keeping intouchable: A community report on the use of mobile phones and social networking by young Aboriginal people in Victoria. Institute for a Broadband-Enabled Society, Communication SoCa. https://www.yumpu.com/en/document/read/34414812/keeping-intouchable-institute-fora-broadband-enabled-society

Hicks, J. \& White, G. (2000). Nunavut: Inuit self-determination through a land claim and public government? In Dahl, J., Hicks, J., Jull, P. (Eds.), Nunavut: Inuit regain control of their lands and their lives (No. 102). IWGIA.

iNaturalist Network (2020). About. iNaturalist. https://www.inaturalist.org/pages/about

Institute for Integrative Science and Health. (n.d.) Retrieved from http://www.integrativescience.ca/Principles/TwoEyedSeeing/

Kirkness, V. J. \& R. Barnhardt (2001). First Nations and higher education: The four r's - respect, relevance, reciprocity, responsibility. In R. Hayoe \& J.Pan (Eds.), Knowledge across cultures: A contribution to dialogue among civilizations. Hong Kong, China: Comparative Education Research Centre, The University of Hong Kong.

Lumby, B. (2010). Cyber-indigeneity: Urban Indigenous identity on Facebook. Australian Journal of Indigenous Education, 39(68), 68-75. https://doi.org/10.1375/S1326011100001150

Means, R. (1980). For America to live Europe must die. The Anarchist Library. http://theanarchistlibrary.org/library/russell-means-for-america-to-live-europe-must-die

Prensky, M. (2001). Digital natives, digital immigrants Part 1. On the Horizon; Bradford, 9(5), 1-6. https://doi.org/10.1108/10748120110424816

Prosper, K. , McMillan, L. J. , Davis, A. A. (2011). Returning to Netukulimk: Mi'kmaq cultural and spiritual connections with resource stewardship and self-governance. The

International Indigenous Policy Journal, 2(4): https://ojs.lib.uwo.ca/index.php/iipj/article/view/7358

Radoll, P. (2014). Cyber-safety and Indigenous youth. Indigenous Law Bulletin, 8(12), 11-14. https://search.informit.com.au/documentSummary; $\mathrm{dn}=398420008048698 ;$;res=IELIND 
Ross, J. B. (2016). Indigenous intergenerational teachings: The transfer of culture, language, and knowledge in an intergenerational summer camp. American Indian Quarterly, 40(3), 216250. https://search-proquestcom.ezproxy.library.dal.ca/docview/1826877043/abstract/45714FB91C1C4796PQ/1?acc ountid=10406

Rearick, N. (2009). Food is something that we gather around: Foodway practices among Arab Americans in Columbus, Ohio [Unpublished Master's thesis].University of Ohio https://etd.ohiolink.edu/!etd.send file?accession $=$ osu1243529334\&disposition $=$ inline

Rice, E. S., Haynes, E., Royce, P., \& Thompson, S. C. (2016). Social media and digital technology use among Indigenous young people in Australia: A literature review. International Journal for Equity in Health, 15(1), 81. https://doi.org/10.1186/s12939016-0366-0

Richards, G., Frehs, J., Myers, E., Van Bibber, M. (2019). The climate change and health adaptation program: Indigenous climate leaders' championing adaptation efforts. Health

Promotion and Chronic Disease Prevention in Canada, 39(4), 127-130. https://www.canada.ca/en/public-health/services/reports-publications/health-promotionchronic-disease-prevention-canada-research-policy-practice/vol-39-no-4-2019/climatechange-health-adaptation-program-indigenous-climate-leaders-championing-adaptationefforts.html

Richmond, C., \& Ross, N. (2009). The determinants of First Nation and Inuit health: A critical population health approach. Health \& Place, 15(2), 403-411. 10.1016/j.healthplace.2008.07.004

Scharmer, O., \& Kaufer, K. (2013). Leading from the emerging future: From ego-system to eco-system economies. Berrett-Koehler Publishers.

Statistics Canada, (2016). The educational attainment of Aboriginal peoples in Canada.

Education. https://www12.statcan.gc.ca/nhs-enm/2011/as-sa/99-012-x/99-012-x2011003_3eng.cfm

Styres, S., \& Zinga, D. (2011). Pedagogy of the land: Tensions, challenges, and contradictions. First Nations Perspectives, 4(1), 59-83. https://mfnerc.org/wpcontent/uploads/2012/11/5 ZingaStyres.pdf 